\title{
Discussing the role of tropical and subtropical moisture sources in extreme precipitation events in the Mediterranean region from a climate change perspective
}

S. O. Krichak et al.

Correspondence to: S. O. Krichak (shimonk@post.tau.ac.il)

The copyright of individual parts of the supplement might differ from the CC-BY 3.0 licence. 
(a) December

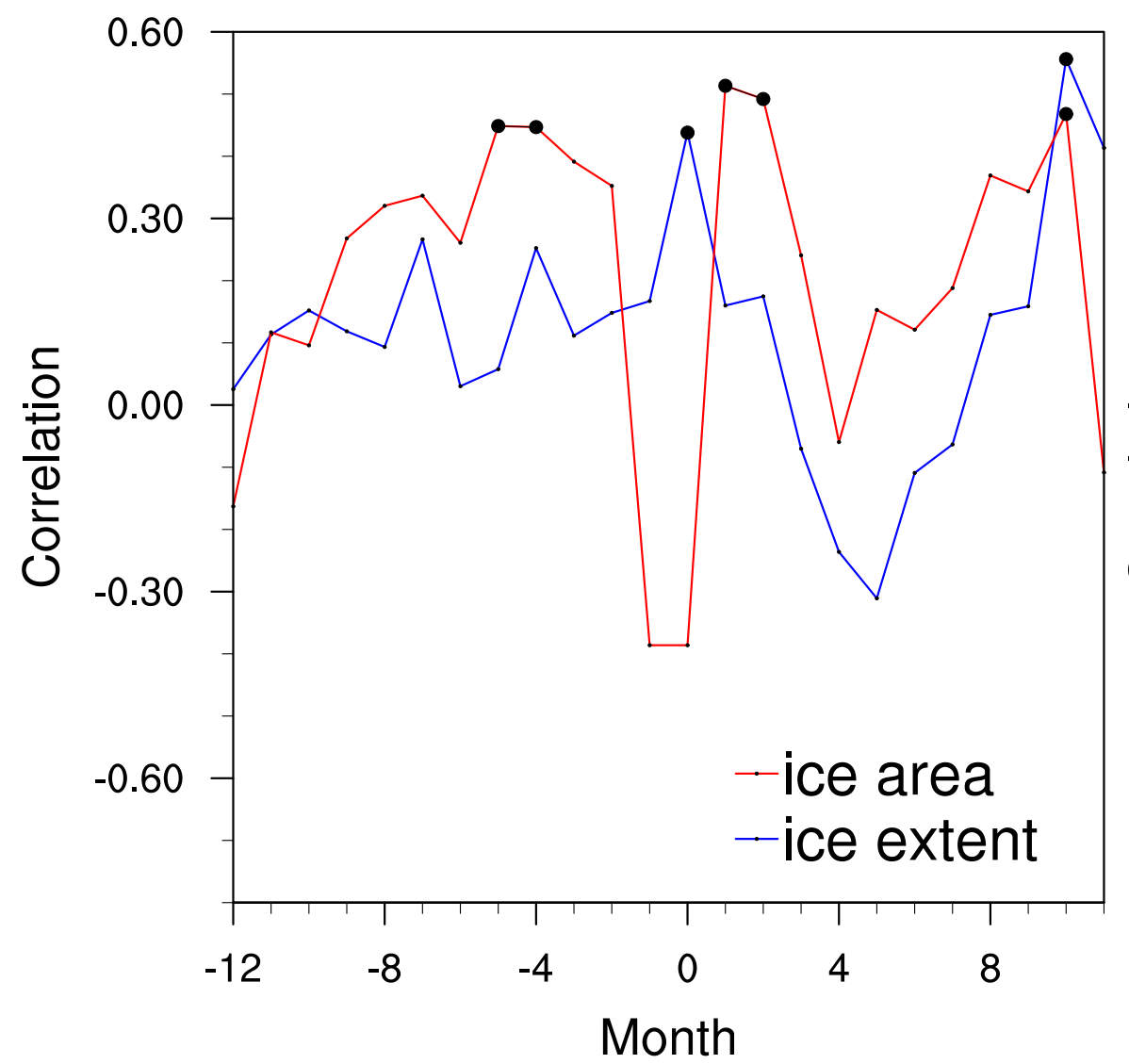

(b) February

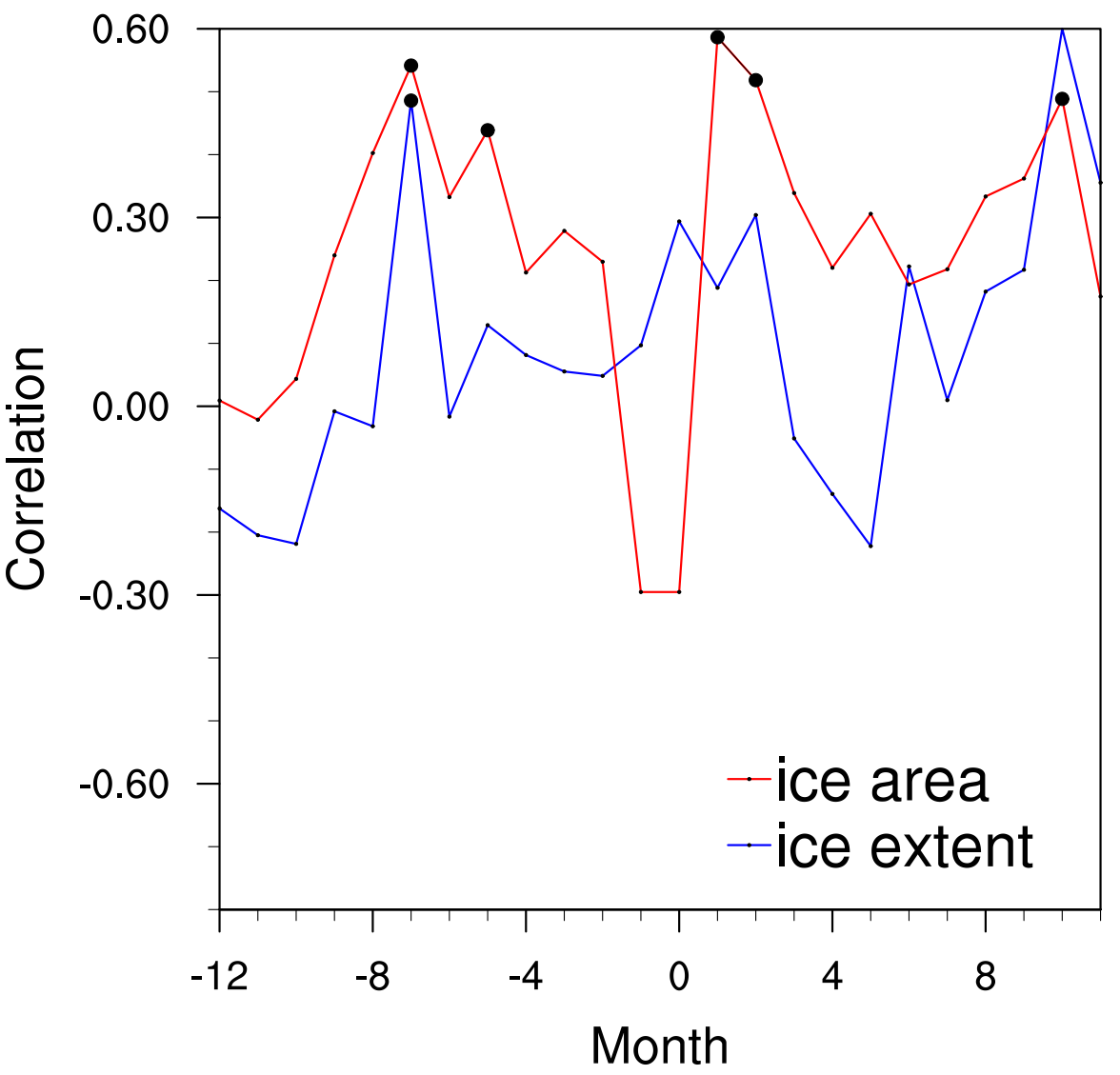

